\title{
High temperatures in parallel or perpendicular wood grain direction: a numerical and experimental study
}

\author{
E. M. M. Fonseca \& L. M. S. Barreira \\ Department of Applied Mechanics, Polytechnic Institute of Bragança, \\ Bragança, Portugal
}

\begin{abstract}
The high vulnerability of wood due to accidental conditions requires a rigorous thermal and mechanical assessment. In this work, an experimental and numerical study will be presented to determine the char-layer evolution in pine wood crosssection, submitted at high temperatures due to an anaerobic process. A non-linear thermal and transient analysis will be conducted using the numerical program. A thermal unit and electro ceramic resistances will be used during the experimental program. The evolution of a char-layer by the orientation of different fibres will be determined. The experimental results obtained with several wood samples will be compared using a numerical program with a finite element formulation. Keywords: pine wood, grain direction, char-layer, high temperatures, experimental study, numerical study.
\end{abstract}

\section{Introduction}

Wood is a natural material and is submitted to many constantly changing influences. Wood as a construction material presents many advantages due its high strength and stiffness to height ratios [1]. The main advantages of timber constructions, relative to the use of other materials, are: ease of construction and maintenance, pleasant appearance, renewable resource, lightweight. The combustion and the chemical phenomena, occurring in wood, during an accidental situation at high temperatures, is a complex study issue. When wood structures are exposed to high temperatures, the burned wood becomes a charlayer which loses all strength, but it delays the rise in temperature in the core of material. The speed at which charring depth advances in the material is called the 
charring rate. This parameter is more or less constant and mainly depends on the density and the moisture content of wood. The charring rate has been studied in different countries by many researchers [2-4] using different types of specimens exposed to the standard time-temperature curve. Safety rules and others guidelines should be useful and used for wood applications. The fire safety of this type of material involves prevention, inhibition and detection. This involves appropriate design rules, installation, construction and maintenance of the wood material in different applications. Wood combustion is slow and regular, and its behaviour is predictable. If wood is submitted to a sufficient heat, a degradation thermal process (pyrolysis) occurs, producing gases accompanied by loss in serviceable cross-section and its weight. The factors which affect the burning behaviour of wood will determine the charring rate. These types of factors consider the following: level of radiant heat exposure, formation of char, moisture content, species and dimensions, as reported by [5]. Design models of wood structures at high temperatures take into account the cross-section loss due to char formation [6]. The stiffness and strength of wood significantly decrease with increasing temperature, as reported by [7]. The interface between charred and noncharred wood is the demarcation plane between black and brown material [8] and is characterized by a temperature of $300^{\circ} \mathrm{C}$, according Eurocode 5 [10]. The objective of this work is to present an experimental program, which could be used to assess the performance time of pine wood cross-sections, during exposure to high temperatures. The determination of char-layer due to high temperatures applied in parallel or perpendicular to wood grain direction will be tested. As reported in [8] the char in normal wood grain direction, corresponds at one-half in parallel direction. When wood fibre is exposed to significant heat its strength decreases.

Different pine cross-sections will be tested and submitted at high temperatures for different fibres' orientation using a heating power unit, based on electrical resistances. The temperature results will be measured through a wood specimen during time heating exposure and char-layer thickness will be determined. Using a finite element analysis method, with appropriated material properties and boundary conditions, reasonable predictions of char-layer thickness can be also provided. This type of analysis and test is important in safety and structural design because it determines how quickly the cross-section size decreases to a critical level at high temperatures.

\section{Physical properties of pine wood}

When exposed to fire, wood is subjected to thermal degradation or pyrolysis process. This process and burning wood have been studied extensively by $[7,9$, 11], among other researches. Generally, the charring rate is almost directly dependent on the time. The charring depth is the distance between the outer surface of the original member and the position of the char-line, as defined in Eurocode 5 [10]. The char-line is the borderline between the char-layer and the residual cross-section. The position of the char-line should be taken as the position of $300^{\circ} \mathrm{C}$ isotherm, according Eurocode 5 [10]. To use wood for its best 
advantage and efficient engineering application, thermal and mechanical properties should be considered. Thermal and physical wood properties play an important role in heat and mass transfer. The physical pine characteristics used in this work for numerical results are reported in [7], and with a density value equal to $509 \mathrm{~kg} / \mathrm{m}^{3}$. These authors tested different wood sections at fire conditions, according to the normalized fire curve ASTME119. The wood sections considered had initial water moisture of between $8 \%$ and $9 \%$.

\section{Thermal proprieties}

The thermal properties of wood vary considerably with temperature. The physical characteristics used for pine wood are referenced by [7], according to table 1. Annex B of Eurocode 5 [10] provides the design values for density, thermal conductivity and specific heat of wood. The values below about $350^{\circ} \mathrm{C}$ represent the properties of wood and above $350^{\circ} \mathrm{C}$ represent the properties of char-layer. The following tables summarize the values of the thermal conductivity, the specific heat and density of wood, assuming initial moisture of $12 \%$. The thermal conductivity values of wood are presented in table 2 ; function of temperature. The thermal conductivity depends on the orientation of the wood grain, as proposed by [12]. According to Spearpoint and Quintiere [12], Forest Products Laboratory [13], the thermal conductivity of wood is approximately $2-$ 2.8 greater along the grain than perpendicular to the grain. Some studies [12], give the range of ratios as between 1.75 and 2.25 . As reported by $[12,14]$ the conductivity of wood along the grain is between 1.5 to 2.8 times the conductivity across the grain. In this work, a value equal to 1.5 of perpendicular or transverse (T) direction was used to calculate the thermal conductivity in parallel or longitudinal (L) direction. Table 1 represents the thermal conductivity used for numerical analysis.

Table 1: $\quad$ Thermal conductivity, $k$.

\begin{tabular}{lll}
\hline \hline Temperature ${ }^{\circ} \mathrm{C}$ & $k(\mathrm{~T}) \mathrm{W} / \mathrm{mK}$ & $k(\mathrm{~L}) \mathrm{W} / \mathrm{mK}$ \\
\hline \hline 20 & 0.12 & 0.18 \\
200 & 0.15 & 0.225 \\
350 & 0.07 & 0.105 \\
500 & 0.09 & 0.135 \\
800 & 0.35 & 0.525 \\
1200 & 1.50 & 2.25 \\
\hline \hline
\end{tabular}

The specific heat of wood increases with temperature but is practically independent of species density [12]. Table 2 represents the values of specific heat according to Eurocode $5[10]$. The peak verified for a value equal to $100^{\circ} \mathrm{C}$ is related to moisture wood evaporation. Moisture in wood affects mass and volume.

The density of wood is primarily dependent on the species and also varies in individual tree [12]. Any wood moisture will also affect the value of density 
174 Safety and Security Engineering IV

Table 2: $\quad$ Specific heat, $C_{p}$.

\begin{tabular}{ll}
\hline \hline Temperature ${ }^{\circ} \mathrm{C}$ & $C_{p} \mathrm{~kJ} / \mathrm{kgK}$ \\
\hline \hline 20 & 1.53 \\
99 & 1.77 \\
99 & 13.60 \\
120 & 13.50 \\
120 & 2.12 \\
200 & 2.00 \\
250 & 1.62 \\
300 & 0.71 \\
350 & 0.85 \\
400 & 1.00 \\
600 & 1.40 \\
800 & 1.65 \\
1200 & 1.65 \\
\hline \hline
\end{tabular}

Table 3: $\quad$ Density ratio, $\rho$.

\begin{tabular}{ll}
\hline \hline Temperature ${ }^{\circ} \mathrm{C}$ & $\rho$ \\
\hline \hline 20 & $1+\mathrm{w}^{*}$ \\
99 & $1+\mathrm{w}^{*}$ \\
120 & 1.00 \\
250 & 0.93 \\
300 & 0.76 \\
350 & 0.52 \\
400 & 0.38 \\
600 & 0.28 \\
800 & 0.26 \\
1200 & 0 \\
\hline${ }^{*}$ w is the initial moisture content.
\end{tabular}

[12]. The wood strength has a direct correlation with density. Density is presented in $\mathrm{kg} / \mathrm{m}^{3}$ for each specified condition. The density ratio design values for dry softwood using a standard fire exposure are given in table 3, according Eurocode 5 [10].

\section{Methodology}

For char-layer determination different wood samples were submitted at high temperatures on the top surface, and two alternative methods were used, a numerical model using the finite element method and an experimental program. 


\subsection{Numerical study}

Differential equations are commonly approximated by the finite element method. This method can be used for a variety of different analyses and structural applications. In this work the finite element program Ansys was used to modelling and analyse the thermal behaviour of pine wood exposed at high temperatures. A finite plane element (Plane 77), with 2 degrees of freedom per node, is used for thermal and nonlinear transient analysis. The non-linearity due to the thermal properties' dependence (tables 2, 3 and 4) will be taken into account in the numerical program. Using the density ratio presented in table 3 and the physical characteristic of pine wood, the density of the considered specie is also determined and used in the numerical analysis. Temperatures will be determined during transient thermal analysis. Thermal analysis will be performed over sample with 500x180x80mm dimensions. Fig. 1 still represents the mesh and the evolution of the temperatures distribution obtained with the numerical program, considering different thermal conductivity properties, as represented in table 1. An initial wood temperature equal to $16^{\circ} \mathrm{C}$ was considered, as measured in laboratorial, and the target temperature measured on the wood surface $T_{\infty}$ is function of an imposed linear heating rate, following the equation:

$$
T_{\infty}=16+\frac{800}{3600} t
$$

In this equation $800^{\circ} \mathrm{C} /$ hour represents the heating rate used and $t$ is the time in seconds.

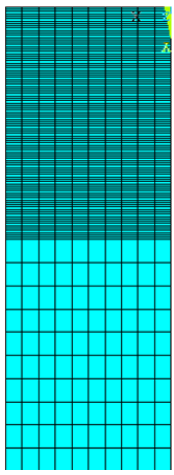

$k(\mathrm{~L})$

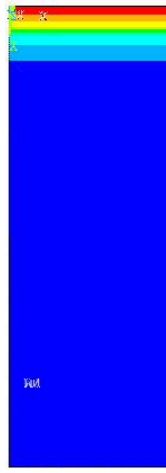

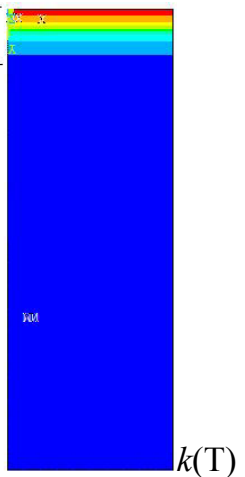

$k(\mathrm{~T})$

Figure 1: Numerical study at one hour.

It can be observed that the submitted specimen at high temperatures, on the top in the small side, at the end of one hour, presents a maximum temperature of $816^{\circ} \mathrm{C}$ in the warm surface. As we can see the distance between the top surface and the core wood is more speed in longitudinal sample. 
Fig. 2 shows the numerical results of the temperature evolution during time heating exposure, using Eq. (1), through different measured points and considering the dependence of thermal conductivity in grain direction.

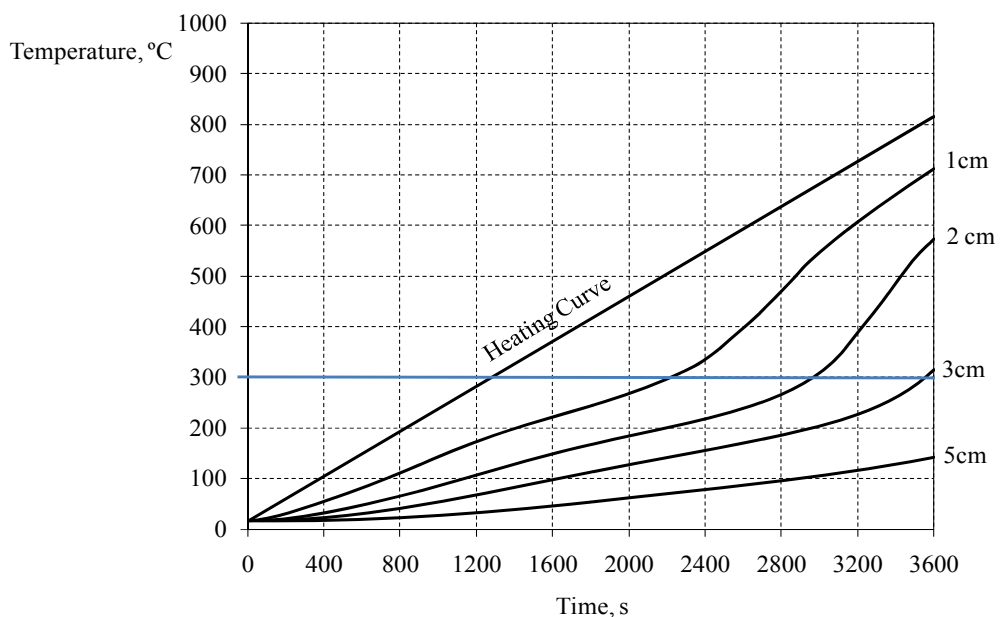

a) $k(\mathrm{~L})$

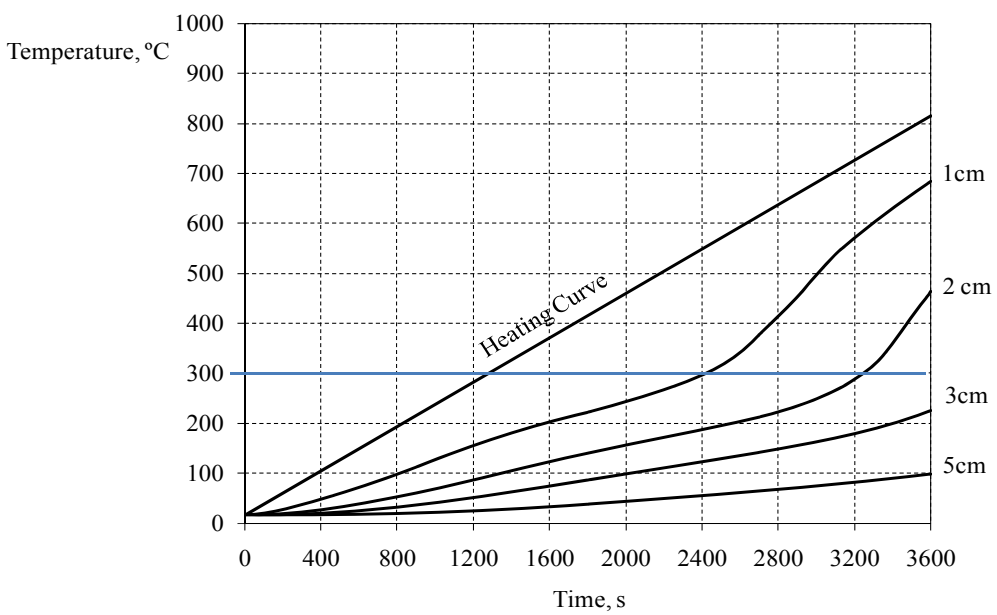

b) $k(\mathrm{~T})$

Figure 2: Temperature-time history.

As can be seen, at $300^{\circ} \mathrm{C}$ only positions at 1 and $2 \mathrm{~cm}$ present a char-layer for different time instants, using thermal conductivity for longitudinal and transverse direction different. One position more has a char-layer formation when high temperature is in longitudinal direction. During one hour at high temperature exposure, the position of $5 \mathrm{~cm}$ presents a lowest value of temperature and represents a normal core wood. These results will be compared with the experimental program with different manufactured samples. 


\subsection{Experimental study}

An experimental program was designed to carry out char-layer determination in pine samples, as presented in Fig. 3.
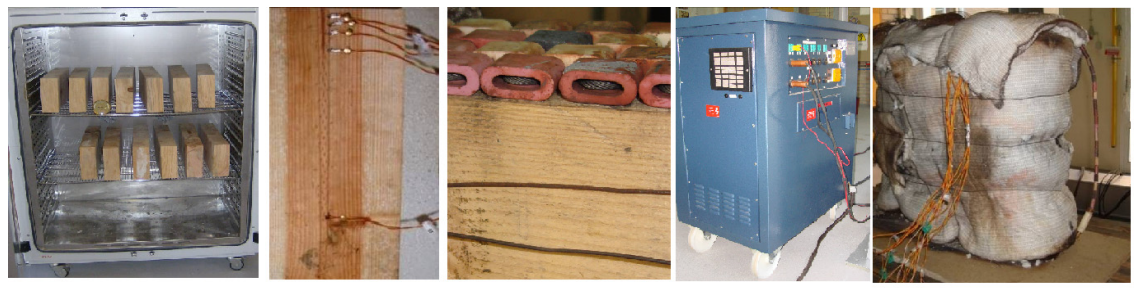

Figure 3: Experimental setup.

The char-layer was measured in five different points using $\mathrm{K}$ thermocouples through an MGCPlus data acquisition system. The temperature was measured at different positions $1,2,3,5$ and $25 \mathrm{~cm}$, from the heating exposure surface using an electrical device system. An electro-ceramic heating system will be used with a thermal power unit of 70kVA. A typical heating curve was used and a programmable controller verifies the temperature during each experimental test. In present work, different pine samples were submitted at one exposure side at high temperatures. Twenty-four samples with dimensions (500x180x80mm) were prepared for experimental tests. Twelve samples are manufactured in longitudinal or parallel to the grain fibres' orientation (L1, L2,... L12) and other twelve in perpendicular grain or transverse orientation (T1, T2,.. T12), as represented in Fig. 4.
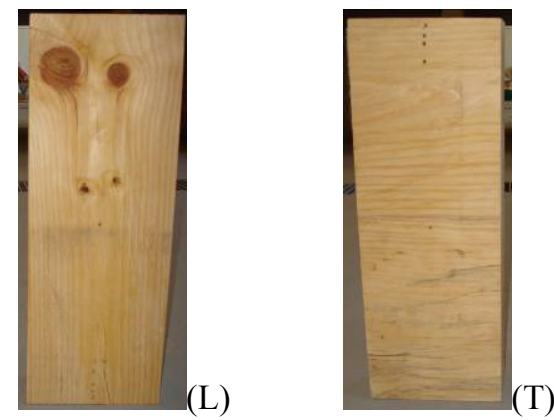

Figure 4: Samples for experimental study.

\section{Results and discussion}

Figs. 5, 6, 7 and 8 represent the temperature evolution obtained for different char measured positions, during one hour at high temperatures exposure. The experimental results are compared with the numerical results. In all figures, time heating curve is also represented. Fig. 5 represents the temperature evolution at $1 \mathrm{~cm}$ from top heating surface, during one hour, for longitudinal samples. 


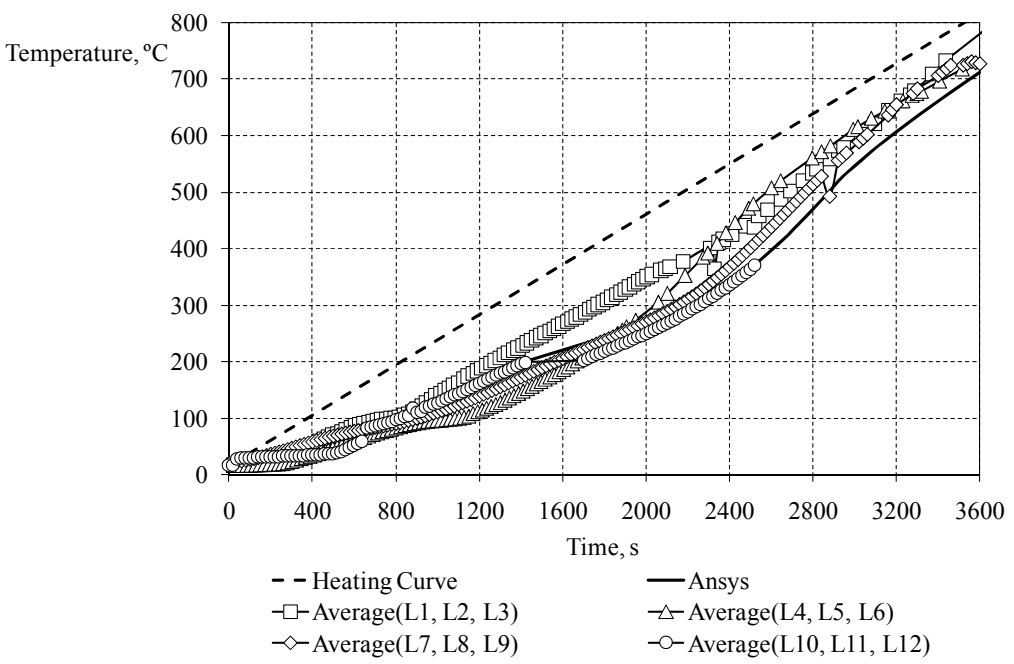

Figure 5: $\quad$ Temperature at $1 \mathrm{~cm}$ from top surface, $(\mathrm{L})$.

Between 1700s-2300s at high temperature exposure, a char-layer is obtained at $1 \mathrm{~cm}$ position from top warm surface. For this position and after one hour, the temperature is between $700-800^{\circ} \mathrm{C}$ for any experimental tests. The obtained temperatures are lesser than the heating unit power curve. On the other hand, the experimental results have a similar behaviour when compared with numerical results. Fig. 6 represents the temperature evolution at $1 \mathrm{~cm}$ from top heating surface during one hour, for transversal samples.

For transversal samples, at $1 \mathrm{~cm}$ from top surface, the char-layer starts between 1800s-2400s. After one hour, the temperature is between $600^{\circ} \mathrm{C}-700^{\circ} \mathrm{C}$.

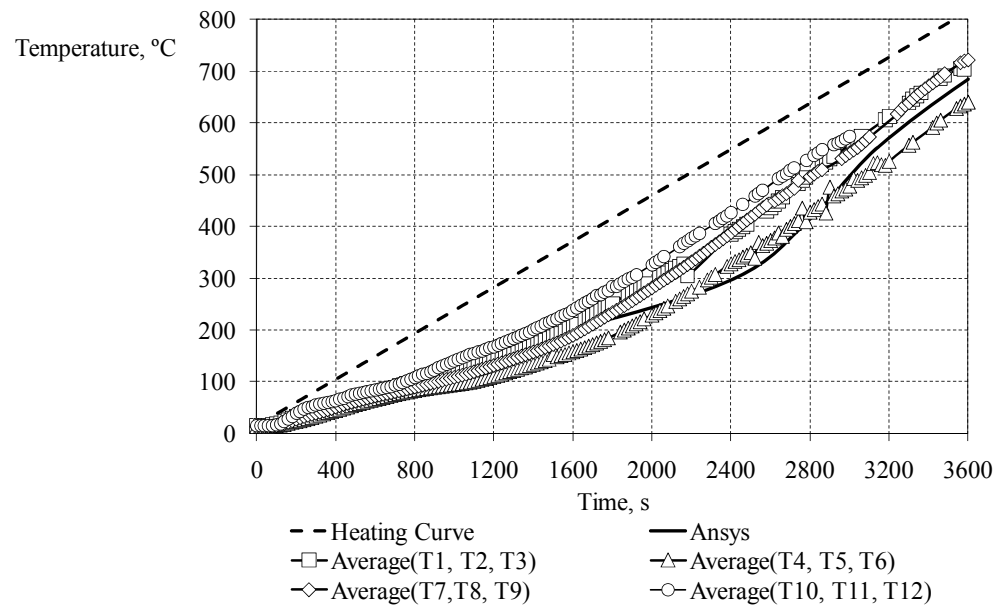

Figure 6: $\quad$ Temperature at $1 \mathrm{~cm}$ from top surface, $(\mathrm{T})$. 
The experimental results are neighbour of the numerical values, when compared with the results in Fig. 5. The wood heating exposure, in the perpendicular grain orientation, delays the char-layer thickness. For $2 \mathrm{~cm}$ from top surface position and for longitudinal samples, the results are presented in Fig. 7.

At this measurement point and after one hour, the temperature is between $500^{\circ} \mathrm{C}$ and $600^{\circ} \mathrm{C}$. After $2900 \mathrm{~s}$ the wood is charred, at $2 \mathrm{~cm}$ from top surface in longitudinal samples. On the other hand, the experimental temperatures are greater when compared with numerical results. The results for this position, but using the perpendicular grain samples manufactured, are represented in Fig. 8.

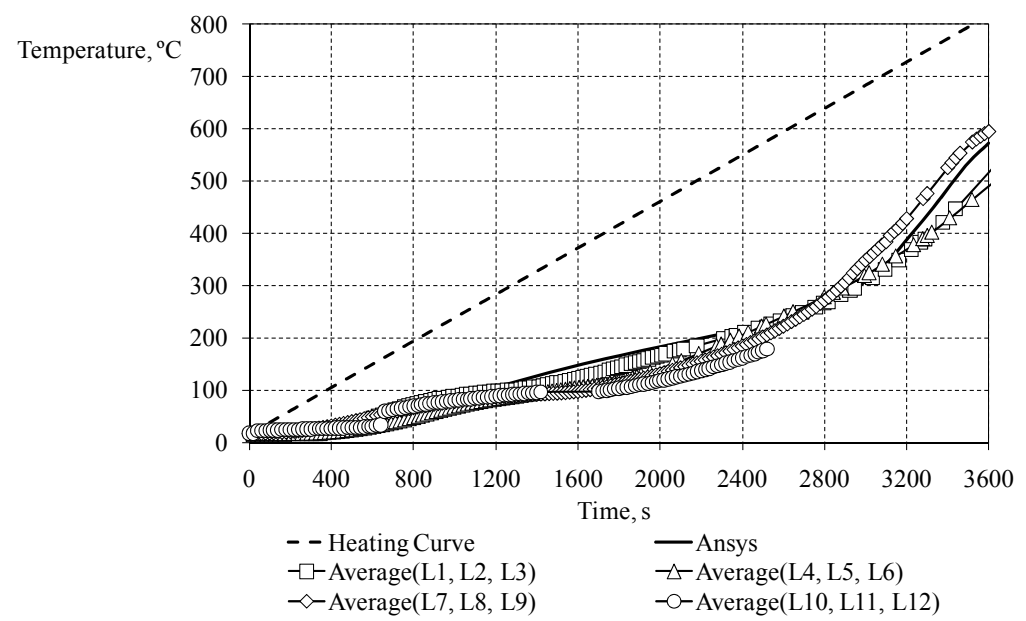

Figure 7: $\quad$ Temperature at $2 \mathrm{~cm}$ from top surface, $(\mathrm{L})$.

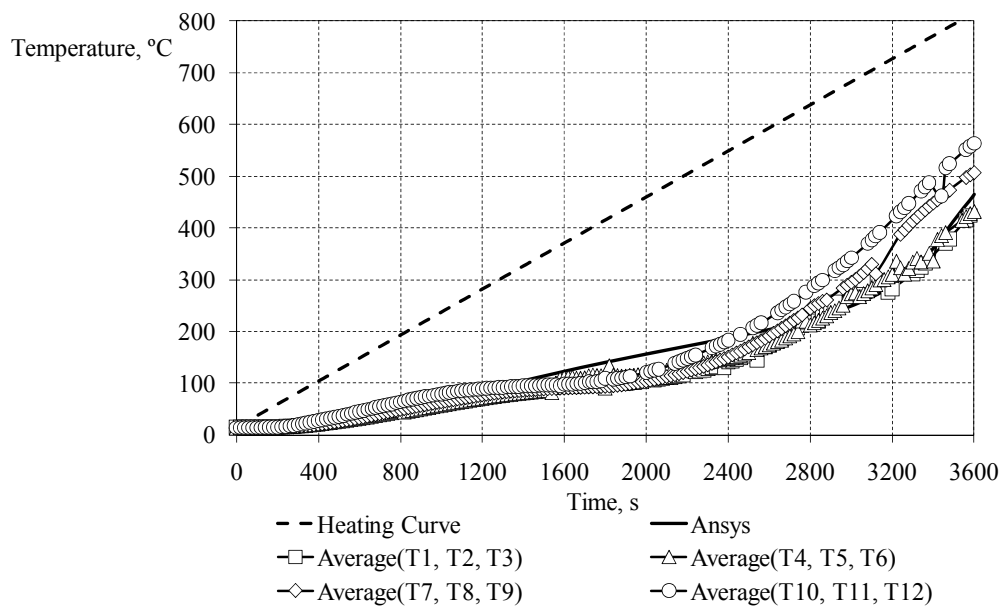

Figure 8: $\quad$ Temperature at $2 \mathrm{~cm}$ from top surface, $(\mathrm{T})$. 
After one hour, the temperature at $2 \mathrm{~cm}$ from top surface is between $450^{\circ} \mathrm{C}$ and $550^{\circ} \mathrm{C}$. The char-layer at $2 \mathrm{~cm}$ occurs between $2900 \mathrm{~s}-3200 \mathrm{~s}$ due high heating exposures. At $3 \mathrm{~cm}$ from top surface, and before one hour, temperature is still bellow $300^{\circ} \mathrm{C}$. For this point and for this time, the wood is noncharred. Fig. 9 and 10 represent the values obtained for this position using longitudinal and transversal samples, respectively.

The measured points at 5 and $25 \mathrm{~cm}$ have low temperatures during one hour at heating exposure. At $25 \mathrm{~cm}$ from top surface, wood cross-sections remain at room temperature, $16^{\circ} \mathrm{C}$. The average values obtained for different measured points during one hour of exposure heating are shown in table 4.

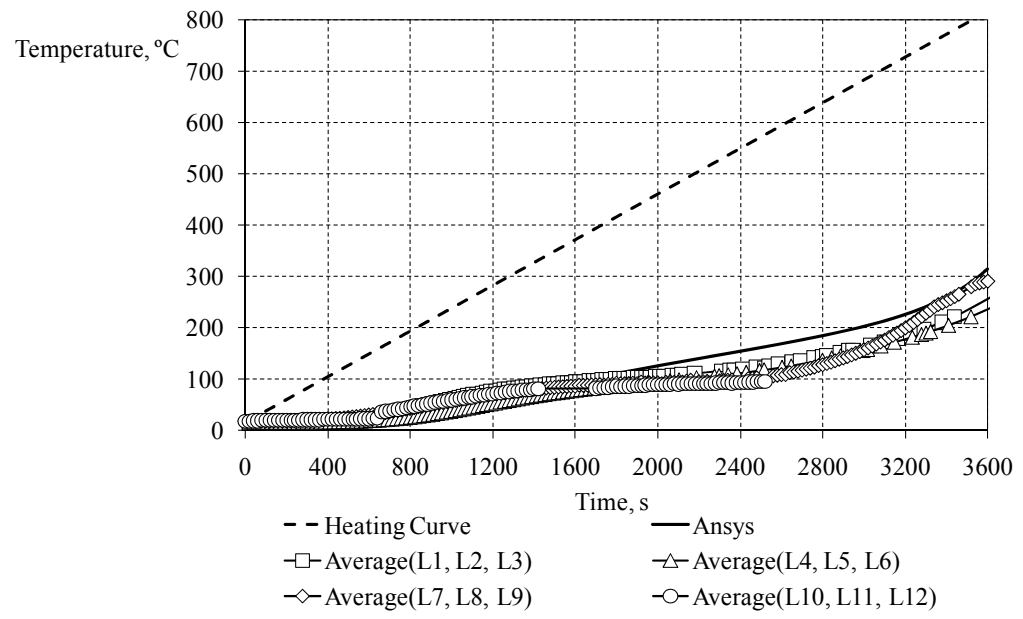

Figure 9: $\quad$ Temperature at $3 \mathrm{~cm}$ from top surface, (L).

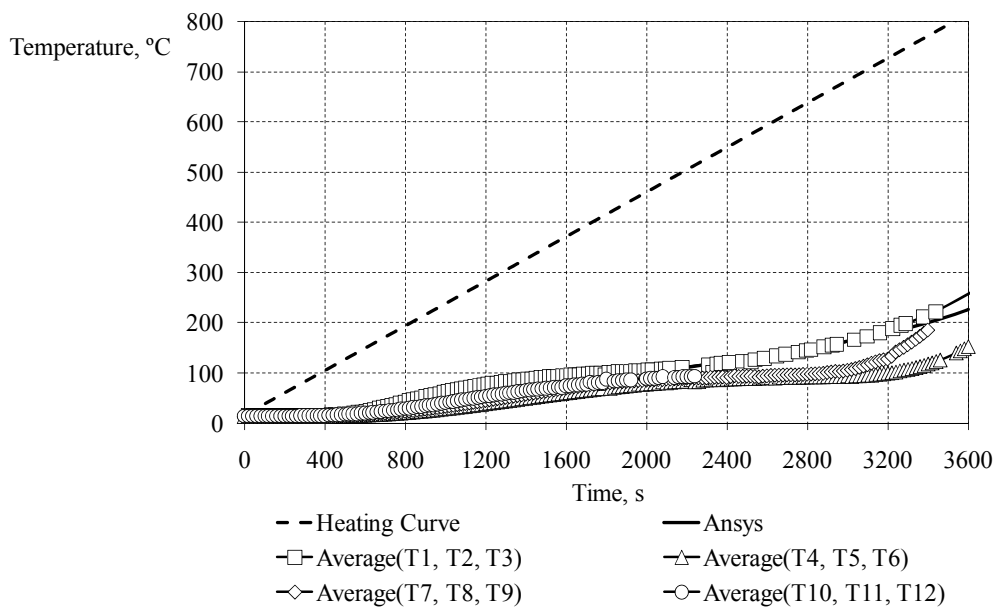

Figure 10: $\quad$ Temperature at $3 \mathrm{~cm}$ from top surface, $(\mathrm{T})$. 
Table 4: Temperatures for one hour of heat exposure.

\begin{tabular}{lllll}
\hline Position, $\mathrm{cm}$ & 1 & 2 & 3 & 5 \\
\hline \hline Pine $(\mathrm{L}),{ }^{\circ} \mathrm{C}$ & 755.2 & 527.5 & 266.0 & 102.0 \\
\hline Pine $(\mathrm{T}),{ }^{\circ} \mathrm{C}$ & 693.5 & 481.2 & 253.8 & 94.2 \\
\hline Difference between $(\mathrm{L})$ and $(\mathrm{T}),{ }^{\circ} \mathrm{C}$ & 61.7 & 46.3 & 12.2 & 7.8 \\
\hline
\end{tabular}

The obtained values allow us to conclude that the warm wood in longitudinal orientation has greater temperature when compared with to the warm wood in transversal orientation, for any measured point. The difference values of temperatures are bigger in the zone of the char-layer thickness, when compared with wood core section. At $25 \mathrm{~cm}$ from top heat surface, temperature remains equal to the initial value of $16^{\circ} \mathrm{C}$. Fig. 11 represents the evolution of the average temperature, for different char-layer position, during one hour and half an hour of thermal front exposure.

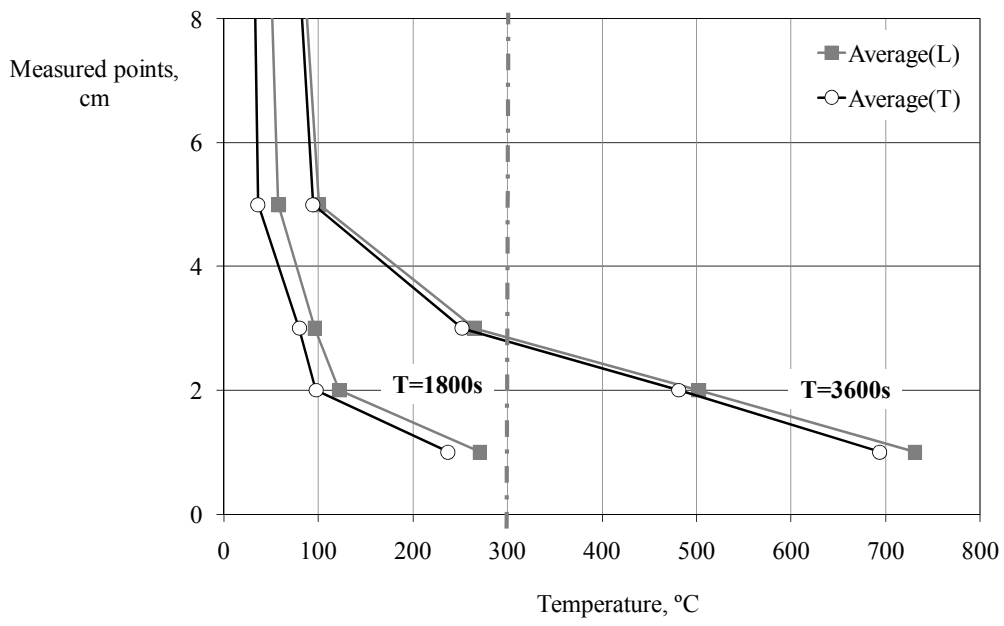

Figure 11: The measured points.

The obtained temperatures values for longitudinal samples are greater than the results obtained with transverse samples, in the same time period. As reported by [7] the char-layer in longitudinal grain orientation is presumed to be higher than transverse orientation. Following some authors $[12,14]$ charring rate of wood along the grain is higher than across the grain with ratio between them ranging from 1.3 to 2.0 .

\section{Conclusions}

Wood exposed at high temperatures will decompose to provide an insulating char-layer that retards further degradation. The load carrying capacity of a 
structural wood member depends upon its serviceable sections [4]. The amount of the cross-section charring is the major in the fire endurance of structural wood members [7]. The pine wood has a greater resistance at high temperatures exposure when compared with other types of woods [4], function of different charring rate and size specimens. This work contributes with an experimental program for evaluation of char-layer thickness in wood elements under high temperatures. Experimental results have shown a difference in charring rate and reproduced reasonably well by numerical results with the thermal properties of Eurocode 5 [10] and a ratio of 1.5 applied by the L/T thermal conductivity. This study it allows to verify the evolution of the temperature and the char-layer throughout a wooden specimen, in different fibres orientation. The experimental results confirm that grain orientation of wood influences the char-layer evolution. The numerical program reveal of great importance also for char-layer determination. The char-layer thickness was calculated with the numerical results obtained from Ansys program and compared with experimental tests.

\section{References}

[1] Racher, P., Laplanche, K., Dhima, D. \& Bouchair, A., Thermo-mechanical analysis of the fire performance of dowelled timber connection, Engineering Structures, 32, pp. 1148-1157, 2010.

[2] Njankouo, J.M., Dotreppe, J.C. \& Franssen J.M., Fire Resistance of Timbers from Tropical Countries and Comparison of Experimental Charring Rates with Various Models, Construction and Building Materials, 19, pp. 376-386, 2005.

[3] Hakkarainen, T., Mikkola, E., Östman, B., Tsantaridis, L., Brumer, H. \& Piispanen, P., InnoFireWood-Innovative eco-efficient high fire performance wood products for demanding applications, VTT, SP Trätek, KTH, 2005.

[4] Fonseca, E.M.M. \& Barreira, L.M.S., Charring rate determination of wood pine profiles submitted to high temperatures, WIT Press, Third International Conference on Safety and Security Engineering, ISBN: 9781-84564-193-1, pp. 449-457, Italy, July, 2009.

[5] Poon, L. \& England, J.P. Literature Review on the Contribution of Fire Resistant Timber Construction to Heat Release Rate - Timber Development Association, Warrington Fire Research Ltd., Project20633, 2b:1-78, 2003.

[6] Frangi, A., Knobloch, M. \& Fontana, M., Fire design of timber slabs made of hollow core elements, Engineering Structures, 31, pp. 150-157, 2009.

[7] White, R.H. \& Dietenberger, M.A., Fire Safety. Wood Handbook: Wood as an Engineering Material, Forest Products Laboratory, USDA, 17, 1999.

[8] Schaffer, E.L., Structural Fire Design: Wood, Forest Products Laboratory, FPL 450:16p, 1984.

[9] Schaffer, E.L., Charring rate of selected woods-transverse to grain, FPL 69, Forest Products Laboratory, Madison, Wisconsin, 1967.

[10] EN 1995-1-2, prEN 1995-1-2 (Eurocode 5), Design of timber structures, Part 1-2 General-Structural fire design. Brussels: CEN, 2003. 
[11] Lipinskas, D. \& Maciulaitis, R., Further Opportunities for Development of the Method for Fire Origin Prognosis, Journal of Civil Engineering and Management, XI(4), pp. 299-307, 2005.

[12] Spearpoint, M.J. \& Quintiere, J.G., Predicting the piloted ignition of wood in the cone calorimeter using an integral model - effect of species, grain orientation and heat flux, Fire Safety Journal, 36, pp. 391-415, 2001.

[13] Forest Products Laboratory, The wood engineering handbook, PrenticeHall, New-Jersey, 1999.

[14] Cachim, P.B. \& Franssen, J.M., Assessment of Eurocode 5 Charring Rate Calculation Methods, Proceedings of the Fifth International Conference on Structures in Fire, Singapore, pp. 676-686, May, 2008. 